\title{
Farinha de mandioca enriquecida com bioproteínas (Saccharomyces cerevisiae), em associação ao feijão e arroz, na dieta de ratos em crescimento
}

\author{
Cassava flour enriched with yeast (Saccharomyces cerevisiae) \\ protein, in association with beans and rice, in the diet \\ of growing rats
}

Anastácia Cavalcanti METRI ${ }^{1}$

Francisca Martins BION²

Silvana Ribeiro Passos de OLIVEIRA ${ }^{3}$

Silvia Maria Limonge LOPES ${ }^{4}$

\section{RE S U M O}

Avaliou-se o efeito da mistura de feijão, arroz e farinha de mandioca enriquecida com bioproteína (Saccharomyces cerevisiae), em ratos wistar machos recém-desmamados $(n=60)$, durante 28 dias. Foram utilizadas as seguintes dietas: experimentais (feijão, arroz e farinha de mandioca enriquecida com leveduras; feijão, arroz e farinha de mandioca comum); controle (farinha de mandioca enriquecida com levedura); e padrão (caseína). Determinaram-se os testes biológicos. Os orgãos foram removidos para análise de pesos úmido e seco (rim esquerdo, baço e amostras do fígado e cérebro), teor de proteína (fígado e cérebro) e histopatologia (fígado, coração e rim direito). Foram ainda quantificados os lipídios totais da carcaça dos animais. Os dados foram estatisticamente avaliados pelo teste Não Paramétrico de Kruskal-Wallis e pelo teste de Comparações Múltiplas $(p<0,05)$. Em todos os parâmetros foram evidenciados melhores resultados com a dieta padrão, seguida das experimentais. Conclui-se que a farinha de mandioca enriquecida com bioproteína poderá ser usada como complemento alimentar para humanos, visando combater as deficiências nutricionais de segmentos populacionais carentes.

Termos de indexação: leveduras, proteína, Saccharomyces cerevisiae, misturas vegetais, enriquecimento alimentar, ratos, farinha de mandioca, alimentos fortificados.

\footnotetext{
1 Prefeitura Municipal de Santa Rita, PB. Rua João Batista de Menezes, 101, Bessa, 58036-115, João Pessoa, PB. Correspondência para/Correspondence to. A.C. METRI.

2 Departamento de Nutrição, Universidade Federal de Pernambuco.

${ }^{3}$ Mestre em Nutrição pela Universidade Federal de Pernambuco.

4 Departamento de Patologia, Universidade Federal de Pernambuco.
} 


\section{A B S T R A C T}

The effect of a mixture of beans, rice and cassava flour enriched with yeast (Saccharomyces cerevisiae) protein was assessed in weanling male Wistar rats $(n=60)$, during 28 days. The following diets were used: experimental (beans, rice and manioc flour with yeast protein; beans, rice and cassava flour without yeast protein); control (cassava flour with yeast protein); and standard (casein). The biological test were determined. The organs were removed for evaluation of wet and dry weights (left kidney, spleen and liver and brain samples), protein levels (liver and brain), and histopathology (heart, right kidney and liver). Carcass total lipids were also recorded. Results were statistically analyzed by the Nonparametric Test of Kruskal-Wallis and the Test of Multiple Comparisons $(p<0.05)$. The highest values for all investigated parameters were found in the casein-fed group, followed by the experimental groups. Data suggest that flour enriched with yeast protein can be recommended as a dietary supplement to eradicate the nutritional deficiency in the poor population.

Index terms: yeasts, proteins, Saccharomyces cerevisiae, vegetable mixtures, food fortification, rats, cassava flour, food, fortifield.

\section{N T R O D U Ç Ã O}

Um dos grandes problemas enfrentados pelas populações de baixa renda em todo o mundo e, principalmente, nos países em desenvolvimento é a inadequação da alimentação, o qual ocasiona quase sempre a desnutrição (Angelis, 1995; Prakash, 1996). O perfil alimentar do brasileiro é simples, em termos de quantidade e qualidade dietética. Dentre os alimentos de origem vegetal mais consumidos pela população destacam-se o feijão, o arroz e a farinha de mandioca, que representam os principais produtos da cesta básica nordestina (Angelis, 1995; Lemos et al., 1996; Sgarbieri, 1996).

Muitos produtos e subprodutos atualmente disponíveis estão sendo estudados com o objetivo de determinar o valor nutritivo, visando sua utilização na dieta alimentar dos seres humanos. Dentre eles estão os microrganismos, considerados fontes promissoras de proteínas e vitaminas, sendo chamados de alimentos não convencionais, proteínas unicelulares, biomassa protéica ou bioproteínas (Miyada \& Lavorenti, 1979).

Parece bastante oportuno o estudo de proteínas não convencionais, como é o caso de produtos obtidos da fermentação microbiológica, buscando analisar a viabilidade de sua incorporação à dieta, como forma de combater as deficiências nutricionais das populações mais carentes, decorrentes da ingestão de alimentos que não atendem aos requerimentos nutricionais. Assim, o propósito deste trabalho foi avaliar a eficiência protéica da farinha de mandioca enriquecida com bioproteínas (Sacharomyces cerevisiae), associada ao feijão e arroz, na manutenção do estado nutricional de ratos, tendo em vista uma futura utilização desta mistura na alimentação humana como uma fonte de enriquecimento protéico.

\section{MATERIALE MÉTODOS}

Foram utilizados três tipos de dietas (experimentais, controle e padrão) elaboradas com os alimentos mais consumidos pela população nordestina, adquiridos nos mercados locais: feijão (Phaseolus vulgaris), arroz (Oryza sativa) e farinha de mandioca comum (Manihot esculenta Crantz). A Indústria Termo Técnica Prolev, localizada na cidade de Recife, PE, forneceu a farinha de mandioca enriquecida com bioproteínas (Saccharomyces cerevisiae), contendo $70 \%$ de farinha de mandioca comum e $30 \%$ de levedura.

Todas as dietas tinham um teor protéico de aproximadamente $10 \%$, sendo chamadas de Dieta 1: Feijão $(6,25 \mathrm{~g} \%$ de proteína $)+$ Arroz $(2,50 \mathrm{~g} \%$ de proteína $)+$ Farinha de mandioca enriquecida com levedura $(1,25 \mathrm{~g} \%$ de proteína); 
Dieta 2: Feijão $(6,25 \mathrm{~g} \%$ de proteína $)+$ Arroz $(2,50 \mathrm{~g} \%$ de proteína $)+$ Farinha de mandioca enriquecida com levedura (2,50g\% de proteína); Dieta 3: Feijão $(6,83 \mathrm{~g} \%$ de proteína $)+$ Arroz $(2,78 \mathrm{~g} \%$ de proteína $)+$ Farinha de mandioca comum $(0,15 \mathrm{~g} \%$ de proteína); Dieta 4 : Feijão $(6,83 \mathrm{~g} \%$ de proteína $)+\operatorname{Arroz}(2,78 \mathrm{~g} \%$ de proteína + Farinha de mandioca comum $(0,30 \mathrm{~g} \%$ de proteína); Dieta 5: Farinha de mandioca enriquecida com levedura $(10,19 \mathrm{~g} \%$ de proteína - controle) e Dieta 6: Caseína $(10,30 \mathrm{~g} \%$ de proteína - padrão).

Os grãos de feijão e arroz foram cozidos em água, por mais ou menos duas horas, dessecados em estufa $\left(60^{\circ} \mathrm{C}\right)$ e pulverizados em moinho, separadamente. A seguir, foram peneirados e misturados para a confecção das dietas, as quais apresentavam-se nutricionalmente balanceadas e praticamente isocalóricas. $\mathrm{Na}$ formulação das rações foram acrescentados celulose, óleo de soja comercial e amido de milho para completar $100 \mathrm{~g}$. As vitaminas e minerais foram adicionados a todas as dietas, segundo as normas preconizadas pelo National Research Council (1978), para o rato (Tabela 1).

Foram selecionados 60 ratos Wistar machos, albinos, provenientes do Biotério de Criação do Departamento de Nutrição da Universidade Federal de Pernambuco (UFPE), recém-desmamados, com peso médio de $49,3 \mathrm{~g} \pm 3 \mathrm{~g}$, acompanhados durante o período de 28 dias. Os animais foram divididos aleatoriamente em seis grupos e submetidos às diferentes dietas, permanecendo em gaiolas individuais, onde recebiam água e ração, ad libitum. Semanalmente, foi feito o controle do peso corporal e da ingestão alimentar, para a determinação dos índices biológicos.

Para as avaliações químicas, a composição centesimal dos alimentos utilizados nas rações (Tabela 2) foi determinada segundo a metodologia recomendada pela Association of Official Analytical Chemists - (AOAC) (Horwitz, 1975). O aminograma ( $\mathrm{g} / 16 \mathrm{~g}$ de nitrogênio) da farinha de mandioca enriquecida foi fornecido pela Prolev e realizado no Instituto Cubano de Investigaciones

Tabela 1. Formulação das dietas experimentais, controle e padrão (g/100g).

\begin{tabular}{|c|c|c|c|c|c|c|}
\hline \multirow{2}{*}{ Componenetes das dietas } & \multicolumn{4}{|c|}{ Experimentais } & \multirow{2}{*}{$\begin{array}{c}\text { Controle } \\
5\end{array}$} & \multirow{2}{*}{$\begin{array}{c}\text { Padrão } \\
6\end{array}$} \\
\hline & 1 & 2 & 3 & 4 & & \\
\hline Caseína $+0,15 \%$ metionina & - & - & - & - & - & 11,38 \\
\hline Feijão carioquinha & 32,21 & 32,21 & 35,21 & 35,21 & - & - \\
\hline Arroz polido & 26,37 & 26,37 & 29,37 & 29,37 & - & - \\
\hline Farinha enriquecida* & 8,17 & 16,34 & - & - & 65,40 & - \\
\hline Farinha de mandioca & - & - & 11,17 & 22,34 & - & - \\
\hline Sais Minerais & 2,59 & 2,40 & 2,67 & 2,67 & 2,47 & 4,00 \\
\hline Fibras & 0,68 & 0,68 & 0,57 & 0,57 & 2,00 & 2,00 \\
\hline Vitaminas lipossolúveis & 1,00 & 1,00 & 1,00 & 1,00 & 1,00 & 1,00 \\
\hline Vitaminas hidrossolúveis & 1,00 & 1,00 & 1,00 & 1,00 & 1,00 & 1,00 \\
\hline Óleo de soja comercial & 7,28 & 7,23 & 7,24 & 7,19 & 7,54 & 8,00 \\
\hline Amido de milho** & 20,70 & 12,77 & 11,77 & 0,65 & 20,59 & 72,47 \\
\hline Calorias (kcal) & 387,80 & 387,98 & 384,24 & 384,24 & 382,32 & 378,10 \\
\hline NDPcal\% & 5,80 & 6,45 & 5,79 & 5,87 & 5,33 & 7,63 \\
\hline
\end{tabular}

\footnotetext{
* Farinha de mandioca enriquecida com proteína de levedura fornecida pela PROLEV. ** q.s.q 100g\%. g\% = refere-se à quantidade de proteína de cada componente da dieta.

Dieta $1=$ Feijão $(6,25 \mathrm{~g} \%)+\operatorname{arroz}(2,50 \mathrm{~g} \%)+$ farinha de mandioca enriquecida com proteína de levedura $(1,25 \mathrm{~g} \%)$.

Dieta 2 = Feijão $(6,25 \mathrm{~g} \%)+\operatorname{arroz}(2,50 \mathrm{~g} \%)+$ farinha de mandioca enriquecida com proteína de levedura $(2,50 \mathrm{~g} \%)$.

Dieta $3=$ Feijão $(6,83 \mathrm{~g} \%)+\operatorname{arroz}(2,78 \mathrm{~g} \%)+$ farinha de mandioca $(0,15 \mathrm{~g} \%)$.

Dieta 4 = Feijão $(6,83 \mathrm{~g} \%)+\operatorname{arroz}(2,78 \mathrm{~g} \%)+$ farinha de mandioca $(0,30 \mathrm{~g} \%)$

Dieta 5 = Farinha de mandioca enriquecida com proteína de levedura $(10,19 \mathrm{~g} \%)$ - controle.

Dieta 6 = Caseína $(10,30 \mathrm{~g} \%)$ - padrão.
} 
de los Derivados de la Caña de Azúcar (ICIDCA, 1996). Também foi efetuado o controle microbiológico da farinha de mandioca enriquecida com bioproteínas (Saccharomyces cerevisiae), de acordo com as normas oficiais do Ministério da Saúde (1997). Para a contagem das colônias de coliformes totais e fecais, as amostras em solução salina $(0,85 \%)$ foram colocadas em placas de petrifilme $\left(10^{-1}\right.$ e $\left.10^{-2}\right)$ e em seguida incubadas em estufa a $35^{\circ} \mathrm{C} / 24$ horas; para contagem de bolores e leveduras, as amostras foram incubadas a $25^{\circ} \mathrm{C} / 3-5$ dias.

Nas análises biológicas, para avaliar $\mathrm{O}$ Coeficiente de Eficácia Alimentar (CEA), Coeficiente de Eficácia Protéica (CEP) e Utilização Líquida de Proteína (ULP), utilizou-se a Técnica de Campbell (Campbell, 1963). As fezes foram recolhidas durante 28 dias, dessecadas em estufa $\left(105^{\circ} \mathrm{C} / 3\right.$ dias), pesadas até valor constante e, em seguida, trituradas, para determinação do nitrogênio pelo método de Kjeldahl (Horwitz, 1975). Com os resultados obtidos estimou-se a digestibilidade aparente das dietas.

Para os estudos bioquímicos e histológicos, após 49 dias de idade, os ratos foram anestesiados e os órgãos (fígado, cérebro, coração, baço e rim) foram removidos. O fígado, o cérebro, o baço e o rim esquerdo foram dessecados $\left(100^{\circ} \mathrm{C}\right)$ e pesados até valor constante, a fim de obter o peso seco. Determinou-se o teor protéico de uma amostra do fígado e do cérebro (Lowry et al., 1951). Realizou-se o exame histopatológico, no qual os órgãos (coração, rim direito e outra amostra do fígado) foram colocados em solução formalina a $10 \%$ para fixação, e, em seguida, foram seccionados, embebidos em parafina e corados em hematoxilina-eosina (Contran et al., 1994). Na carcaça, dosaram-se os teores de lipídios totais (Enteman, 1957).

Para a análise estatística, aplicou-se o Teste Não Paramétrico de Kruskal-Wallis, e o Teste de Comparações Múltiplas foi utilizado para a confirmação dos dados (Gomes, 1985). O nível de rejeição da hipótese nula foi $5 \%$.

\section{RESULTADOS}

A análise microbiológica em duas amostras da farinha de mandioca enriquecida com bioproteínas (Saccharomyces cerevisiae) evidenciou valores de coliformes totais de $0,7 \mathrm{~g}$ e $24 \mathrm{~g}$, fecais de $0,0 / \mathrm{g}$, bolores e leveduras de 40,0 $\mathrm{UFC} / \mathrm{g}$ e $1,2 \times 10^{2} \mathrm{UFC} / \mathrm{g}$, dentro dos padrões estabelecidos pelos órgãos oficiais (Ministério..., 1987).

Quanto à composição dos aminoácidos das proteínas (Tabela 3), aferida através do cômputo químico da farinha de mandioca enriquecida com bioproteínas (Saccharomyces cerevisiae), constatou-se como primeiro aminoácido limitante a metionina (62\%) e como segundo a leucina (75\%).

Em relação às ingestões alimentares $\mathrm{e}$ protéicas, CEA, CEP, ULP e digestibilidade aparente (Dap), verificou-se superioridade da dieta

Tabela 2. Composição centesimal dos alimentos utilizados na confecção das dietas experimentais, controle e padrão (\%).

\begin{tabular}{lcccccc}
\hline Alimentos & PTN & HC & LP & F I & SM & UM \\
\hline Farinha rica & 15,29 & 71,96 & 0,71 & - & 2,34 & - \\
Farinha comum & 1,36 & 83,24 & 0,40 & - & 3,70 & - \\
Feijão carioca & 19,40 & 66,29 & 1,63 & 0,40 & 0,50 & - \\
Arroz polido cru & 9,48 & 79,70 & 0,60 & - & - & - \\
Caseína & 84,13 & - & 0,20 & - & - \\
Amido & 1,00 & 87,84 & & - \\
\hline
\end{tabular}

PTN = proteínas; FI = fibra; $H C=$ hidratos de carbono; SM = sais minerais; $L P=$ lipídios; $U M=$ umidade; $(-)=$ não determinado. Farinha rica = farinha de mandioca enriquecida com proteína de levedura; Farinha comum = farinha de mandioca; Amido de milho com nome comercial = maisena; Análise realizada no Departamento de Nutrição da UFPE (Laboratório de Experimentação e Análise de Alimentos - LEALL). 
padrão e inferioridade da controle (Tabela 4). Entre os grupos experimentais, há semelhança estatística entre as dietas 1 e 2; entretanto, maiores valores foram obtidos para os animais alimentados com a dieta 2 em relação à 1. Quanto aos coeficientes de digestibilidade, foram de aproximadamente $94 \%$ para o grupo caseína; contudo, nas dietas 1, 2, 3, 4 e 5, atingiram 74\%, $88 \%, 65 \%, 68 \%$ e $61 \%$, respectivamente.

Outro parâmetro analisado foi a curva de crescimento (Figura 1) dos animais submetidos às diferentes dietas. No final de 28 dias de experimento, após desmame, o maior peso foi o dos ratos alimentados com a dieta 6 , seguida das dietas 2, 1, 3, 4 e 5. Entre as experimentais, a dieta 2 (Feijão $(6,25 \mathrm{~g} \%$ de proteína) + Arroz $(2,50 \mathrm{~g} \%$ de proteína $)+$ Farinha de mandioca enriquecida com levedura $(2,50 \mathrm{~g} \%$ de proteína)) apresentou melhor resultado. A adição de duas diferentes proporções de farinha de mandioca comum (dietas 3 e 4) ao feijão e arroz não interferiu no peso dos animais.

Os teores de lipídios totais da carcaça dos animais alimentados com as dietas experimentais $1(15,80 \% \pm 0,45)$ e $2(17,75 \% \pm 0,25)$ apresentaram ligeira superioridade quando comparados aos das dietas $3(13,25 \% \pm 0,56) \mathrm{e}$ $4(14,00 \% \pm 0,36)$, enquanto o peso magro foi maior para os animais submetidos às dietas 2 $(130,00 \mathrm{~g} \pm 4,56)$ e padrão $(191,58 \mathrm{~g} \pm 4,32)$ quando relacionados com as dietas 1 $(104,36 \mathrm{~g} \pm 2,33), 3(102,06 \mathrm{~g} \pm 3,69), 4$ $(102,58 \mathrm{~g} \pm 5,36)$ e controle $(79,88 \mathrm{~g} \pm 2,31)$.

Tabela 3. Cômoputo químico dos aminoácidos da farinha de mandioca enriquecida com proteína de levedura.

\begin{tabular}{lccc}
\hline \multirow{2}{*}{ Aminoácidos } & \multicolumn{2}{c}{$\mathrm{mg} / \mathrm{g}$ nitrogênio } & Cômputo Químico \\
\cline { 2 - 4 } & Farinha Teste* & Caseína & 97 \\
\hline Lisina & 30,05 & 31,01 & 105 \\
Treonina & 18,73 & 17,78 & 62 \\
Metionina & 6,63 & 10,66 & - \\
Cistina & - & 1,38 & - \\
Triptofano & 3,90 & 20,66 & 87 \\
Isoleucina & 17,95 & 36,34 & 75 \\
Leucina & 27,32 & 25,74 & 80 \\
Valina & 20,68 & 19,99 & 80 \\
Fenilalanina & 16,00 & & \\
\hline
\end{tabular}

* Farinha de mandioca enriquecida com proteína de levedura.

Tabela 4. Ingesta Alimentar e Protéica, Coeficiente de Eficácia Aparente das dietas experimentais, controle e padrão, durante 28 dias.

\begin{tabular}{ccccccc}
\hline Dietas & Ingesta Alimentar $(\mathrm{g})$ & Ingesta Protéica $(\mathrm{g})$ & CEA $(\mathrm{g} / \mathrm{g})$ & CEP $(\mathrm{g} / \mathrm{g})$ & ULP $(\mathrm{g} / \mathrm{g})$ & Dap $(\%)$ \\
\hline Dieta 1 & $304,62^{\mathbf{b}} \pm 22,96$ & $31,07^{\mathbf{b}} \pm 6,40$ & $0,23^{\mathbf{b}} \pm 0,04$ & $2,21^{\mathbf{b}} \pm 0,12$ & $3,38^{\mathbf{b}} \pm 0,35$ & $74^{\mathbf{c}}$ \\
Dieta 2 & $351,82^{\mathbf{a b}} \pm 26,64$ & $40,04^{\mathbf{a b}} \pm 4,78$ & $0,28^{\mathbf{a}} \pm 0,02$ & $2,46^{\mathbf{a b}} \pm 0,15$ & $3,45^{\mathbf{a b}} \pm 0,28$ & $88^{\mathbf{b}}$ \\
Dieta 3 & $289,4^{\mathbf{b}} \pm 28,84$ & $28,66^{\mathbf{b}} \pm 2,85$ & $0,24^{\mathbf{b}} \pm 0,04$ & $2,38^{\mathbf{b}} \pm 0,17$ & $3,35^{\mathbf{b}} \pm 0,23$ & $65^{\mathbf{d}}$ \\
Dieta 4 & $277,93^{\mathbf{b}} \pm 25,23$ & $27,57^{\mathbf{b}} \pm 3,58$ & $0,24^{\mathbf{b}} \pm 0,06$ & $2,42^{\mathbf{b}} \pm 0,13$ & $3,42^{\mathbf{b}} \pm 0,26$ & $68^{\mathbf{c}}$ \\
Dieta 5 & $228,83^{\mathbf{c}} \pm 21,15$ & $23,32^{\mathbf{c}} \pm 4,56$ & $0,19^{\mathbf{c}} \pm 0,02$ & $1,84^{\mathbf{c}} \pm 0,15$ & $2,90^{\mathbf{c}} \pm 0,21$ & $61^{\mathbf{d}}$ \\
Dieta 6 & $423,96^{\mathbf{a}} \pm 29,63$ & $43,67^{\mathbf{a}} \pm 2,36$ & $0,38^{\mathbf{a}} \pm 0,03$ & $3,72^{\mathbf{a}} \pm 0,12$ & $4,91^{\mathbf{a}} \pm 0,25$ & $94^{\mathbf{a}}$ \\
\hline
\end{tabular}

Letras diferentes, na mesma coluna, indicam diferenças estatísticas ao nível de $5 \%$ de probabilidade no Teste de Kruskal-Wallis. ( $\mathrm{n}=10$ ). $\mathrm{g} \%=$ refere-se à quantidade de proteína de cada componente da dieta.

Dieta $1=$ Feijão $(6,25 \mathrm{~g} \%)+\operatorname{arroz}(2,50 \mathrm{~g} \%)+$ farinha de mandioca enriquecida com proteína de levedura $(1,25 \mathrm{~g} \%)$

Dieta 2 = Feijão $(6,25 \mathrm{~g} \%)+\operatorname{arroz}(2,50 \mathrm{~g} \%)+$ farinha de mandioca enriquecida com proteína de levedura $(2,50 \mathrm{~g} \%)$

Dieta $3=$ Feijão $(6,83 \mathrm{~g} \%)+\operatorname{arroz}(2,78 \mathrm{~g} \%)+$ farinha de mandioca $(0,15 \mathrm{~g} \%)$.

Dieta 4 = Feijão $(6,83 \mathrm{~g} \%)+\operatorname{arroz}(2,78 \mathrm{~g} \%)+$ farinha de mandioca $(0,30 \mathrm{~g} \%)$.

Dieta 5 = Farinha de mandioca enriquecida com proteína de levedura $(10,19 g \%)$ - controle.

Dieta 6 = Caseína $(10,30 \mathrm{~g} \%)$ - padrão. 


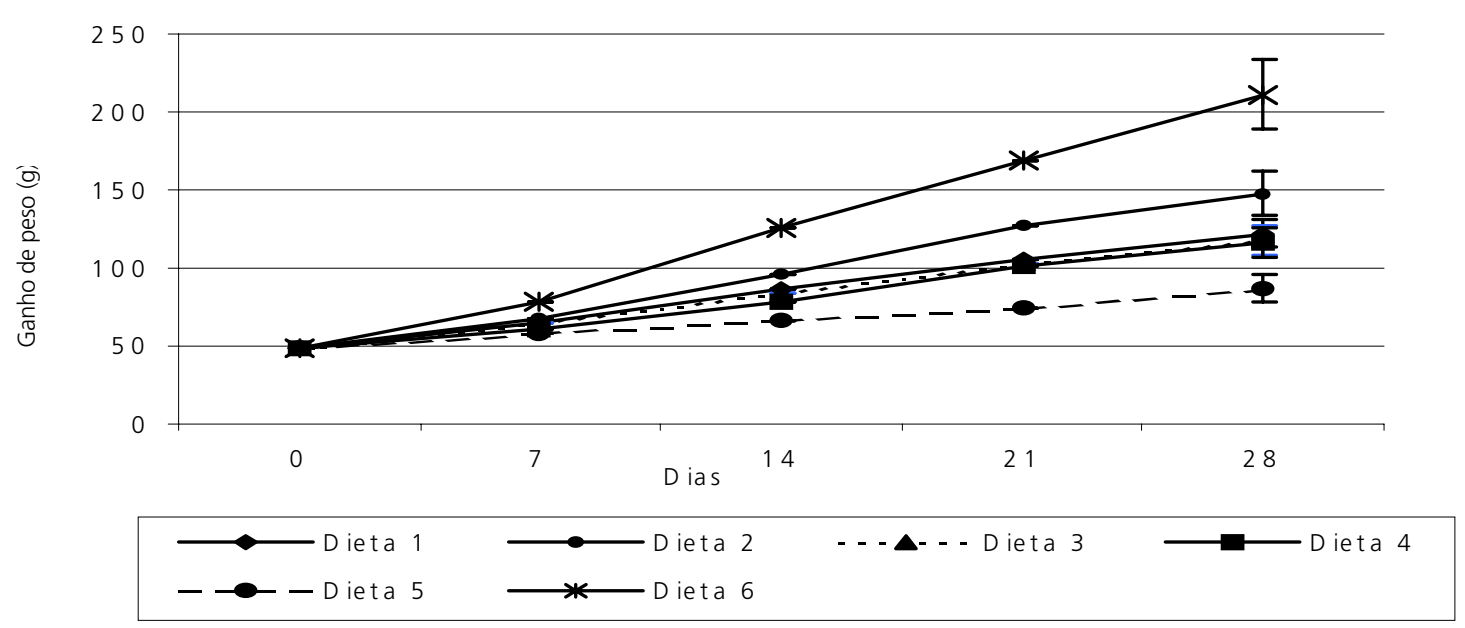

Figura 1. Curva de crescimento dos ratos alimentados com as dietas experimentais, controle e padrão, durante 28 dias.

Pode-se verificar a mesma tendência de variação dos parâmetros analisados anteriormente, em relação aos teores de proteínas do fígado e cérebro dos animais submetidos às dietas experimentais, controle e padrão. A dieta caseína apresentou, para a proteína do fígado $(160,02 \mathrm{mg} / \mathrm{g} \pm 3,52)$ e proteína do cérebro $(139,24 \mathrm{mg} / \mathrm{g} \pm 4,23)$, maiores valores que os das dietas controle $(118,99 \mathrm{mg} / \mathrm{g} \pm 7,86 \mathrm{e}$ $106,88 \mathrm{mg} / \mathrm{g} \pm 6,53)$ e experimentais: 1 $(128,65 \mathrm{mg} / \mathrm{g} \pm 7,19$ e $119,08 \mathrm{mg} / \mathrm{g} \pm 5,63), 3$ $(120,94 \mathrm{mg} / \mathrm{g} \pm 7,63)$ e $4(127,03 \mathrm{mg} / \mathrm{g} \pm 8,71)$; no entanto, foi estatisticamente semelhante à dieta experimental $2(141,00 \mathrm{mg} / \mathrm{g} \pm 6,10 \mathrm{e}$ $128,03 \mathrm{mg} / \mathrm{g} \pm 6,23)$. Com relação à dieta controle, esta obteve menores teores, quando comparada às demais.

Os valores dos pesos úmido e seco dos órgãos estudados evidenciaram uma melhora significativa no grupo caseína em relação às demais dietas. A dieta 2, entre as experimentais, foi a que permaneceu sempre em maior evidência, revelando os melhores resultados. Quanto ao fígado, cérebro e rim, observou-se praticamente um paralelismo entre as perdas do peso úmido para o seco em todas as dietas estudadas; no caso do baço, apenas o peso úmido não foi significativo.
Analisando-se o peso relativo dos órgãos (peso úmido do órgão relacionado ao peso corporal, expresso como percentual da dieta padrão), verificou-se na dieta controle um aumento acentuado do peso do cérebro, rim e baço e uma leve diminuição do fígado, em comparação aos demais grupos.

O estudo histopatológico demonstrou que 58 animais apresentaram uma histologia normal nas secções das amostras do tecido hepático; em apenas dois animais (um submetido à dieta controle e o outro à dieta 4) foi evidenciada esteatose hepática. Nas secções do coração e rim observou-se padrão de normalidade.

\section{DISC U S S Ã O}

A composição centesimal dos alimentos utilizados nas dietas evidenciou um teor relativamente maior de proteínas na farinha de mandioca enriquecida com bioproteínas (Saccharomyces cerevisiae), quando comparada comum, demonstrando ser viável enriquecer a farinha de mandioca com proteína de levedura (Antai, 1990).

Dentre todos os nutrientes analisados nas dietas testadas, as proteínas foram os de maior 
importância. Segundo Angelis (1995), a composição dos aminoácidos destas proteínas deve apresentar-se proporcionalmente balanceada, pois tanto a falta como o excesso de um ou mais destes compostos implicam em desequilíbrio dinâmico protéico. Identificou-se baixo conteúdo dos aminoácidos sulfurados, fato semelhante ao ocorrido com Mariath \& Zucas (1980) e Mariath (1983b), os quais encontraram um cômputo químico para os aminoácidos sulfurados totais da levedura na ordem de $61 \%$, em relação ao padrão da Food and Agriculture Organization (FAO). Outros pesquisadores confirmam estes resultados, como Benassi et al. (1990), Gálvez et al. (1990), Pacheco et al. (1997).

Os valores encontrados para o CEP (Tabela 3), são semelhantes aos relatados por Pacheco et al. (1997), que testaram a proteína da levedura (Saccharomyces sp) em ratos, ao nível de 10\%; Hernandez et al. (1996) obtiveram valores superiores para as células de leveduras submetidas ao tratamento de perclorato de sódio, quando comparadas com leveduras puras; e, para Poó \& Millán (1990), os valores do CEP $(2,7 g)$ e ULP $(3,1 \mathrm{~g})$ apresentaram-se sem nenhum prejuízo para o peso, quando a levedura foi empregada até $25 \%$.

Os resultados citados neste trabalho estão baseados em diferentes pesquisas, nas quais foram constatados baixos coeficientes biológicos da proteína de fontes vegetais isoladas (feijão, arroz e soja), quando comparados com a caseína (Lam-Sanchez et al., 1993/1994; Hernandez et al., 1996; Bion et al., 1997).

Quanto à digestibilidade, os dados estão de acordo com os obtidos por Beausset (1995), que encontrou uma digestibilidade entre $60 \%$ e $80 \%$ para proteínas vegetais e, conforme se poderia esperar, de $90 \%$ para a dieta padrão, por ser elaborada com proteína de boa qualidade e apropriada para a espécie em estudo. A literatura confirma o achado em relação à digestibilidade de diferentes leveduras, relatando valores em torno de $60 \%$ a $89 \%$ (Mariath \& Zucas, 1980; Mariath \& Zucas,1983b; Pacheco et al., 1997), bem como de outras proteínas vegetais (Carias et al., 1995; Hernandez et al., 1996; Sarwar, 1997).

Acredita-se que o melhor ganho de peso, na curva de crescimento, dos animais alimentados com a dieta 2 deve-se à melhoria do perfil de aminoácidos contidos na mistura, sendo este resultado semelhante ao constatado por Mariath \& Zucas (1980). O fato demonstra a influência tanto da qualidade como da quantidade das proteínas, tornando possível obter um melhor perfil de aminoácidos essenciais na mistura da dieta 2 (Mariath \& Zucas, 1980; Angelis, 1995).

Os resultados sobre lipídios totais da carcaça e peso magro estão de acordo com os de Grant et al. (1995). Henry et al. (1997), os quais também identificaram alterações entre a mobilização do tecido e o estoque de energia-proteína quando os ratos são submetidos a restrição alimentar. Em razão da escassez de dados analíticos sobre esses parâmetros, nas condições específicas deste estudo, tornou-se difícil comparar os achados com os da literatura.

Com relação aos pesos úmido e seco dos órgãos (fígado, cérebro, rim e baço), vários estudos indicam a superioridade da proteína animal no tocante ao crescimento e desenvolvimento dos órgãos, quando comparada com fontes vegetais (Lourenço et al., 1980; Mariath \& Zucas, 1983a; Bion et al., 1997).

$\mathrm{Na}$ análise do peso relativo dos órgãos, conforme mencionado anteriormente, verificou-se apenas no grupo controle um aumento acentuado dos pesos do cérebro, baço e rim e uma leve diminuição do fígado, em comparação aos demais grupos. Ressalta-se que este mecanismo de adaptação à inanição ou à dieta de baixa qualidade está bastante documentado na literatura (Pessoa et al., 1979; Lourenço et al., 1980; Mariath \& Zucas, 1983a; Belda \& Utrilla, 1985; Guedes, 1985; Póo \& Millan, 1990; Teodósio et al., 1990; Bion et al., 1997), confirmando mais uma vez a superioridade da proteína animal em relação à vegetal. 


\section{O N CLUSÃ O}

Os dados obtidos neste estudo levam a concluir que a farinha de mandioca enriquecida com bioproteínas (Saccharomyces cerevisiae) poderá ser utilizada como complemento alimentar de animais e humanos. No caso das leveduras, consideradas fontes promissoras de proteínas, é de grande importância seu consumo em adição à farinha de mandioca, componente indispensável e relevante da cesta básica do nordestino e um dos alimentos mais consumidos pela população de baixa renda, exatamente aquela que, por limitações econômicas, é submetida a uma dieta inadequada e, por isso, está quase sempre sujeita a carências nutricionais, em especial a desnutrição.

Contudo, tendo em vista os aspectos toxicológicos envolvidos e até mesmo os hábitos alimentares da população, é recomendável a realização de pesquisas mais abrangentes e profundas, abordando outros aspectos, como a quantidade e freqüência de ingestão, a fim de avaliar com absoluta segurança a viabilidade da sua inclusão na dieta humana.

\section{A GRADECIMENTOS}

Os autores agradecem a colaboração da bibliotecária Cristina Malta pela revisão lingüística e documental do trabalho e ao apoio científico/financeiro do Conselho Nacional de Desenvolvimento Científico e Tecnológico (CNPq).

\section{REFERÊ NCIAS BIBLIOGRÁFICAS}

ANGELIS, R.C. Valor nutricional das proteínas; métodos de avaliação. Cadernos de Nutrição, São Paulo, v.10, p.8-29, 1995

ANTAI, S.P. Enrichment of nutrient quality of cassava (Manihot esculenta Crantz) with microbial proteins. Plant Foods for Human Nutrition, v.40, p.289-296, 1990.

BEAUSSET, I. Estudio de las bases científicas para el uso de alimentos alternativos en la nutrición humana. Brasília : INAN, 1995.
BELDA, M.C.R., UTRILLA, L.S. Aspectos morfológicos e histoquímicos do fígado de ratos submetidos à desnutrição protéico-calórica. Revista de Ciências Farmacêuticas, São Paulo, v.7, p.7-16, 1985.

BENASSI, V.T., CAMARGO, C.R.O., CIACCO, C.F. Caracterização química e redução do conteúdo de ácidos nucléicos das células de levedura (Saccharomyces spp) provenientes da produção de álcool de cana. Ciência e Tecnologia de Alimentos, Campinas, v.10, p.249-260, 1990.

BION, F.M., PESSOA, D.C.N.P., LAPA, M.A.G., CAMPOS, F.A.C.S., ANTUNES, N.L.M., LOPES, S.M.L. Uso de uma multimistura como suplemento alimentar: estudo em ratos. Archivos Latinoamericanos de Nutrición, Guatelamala, v.47, p.242-247, 1997.

BRASIL. Ministério da Saúde. Portaria n 451, 19 de setembro de 1997. Aprova o regulamento técnico e princípios gerais para o estabelecimento de critérios e padrões microbiológicos para alimentos. Diário Oficial da União, Brasília, 2 jul. 1998.

CAMPBELL, J.A. Method for determination of PER \& NPR. In: FOOD AND NUTRITION BOARD. Committee on Protein Quality. Evaluation of protein quality. Washington DC, 1963. p.31-32.

CARIAS, D., CIOCCIA, A.M., HEVIA, P. Grado de concordancia entre la digestibilidad de proteínas animales y vegetales medidas in vivo e in vitro y su efecto sobre el cómputo químico. Archivos Latinoamericanos de Nutrición, Guatemala, v.45, p.111-116, 1995

CONTRAN, R.S., ROBBINS, S.L., KUMAR, V. Pathologic basis of disease. 5.ed. Philadelphia: McGraw-Hill, 1994. 1400p.

ENTEMAN, C. General procedures for separating lipid components of tissue. In: COLOWICK, S.P., KAPLAN, N.O. Methods in enzimology. New York : Academic Press, 1957. v.3, p.299-317.

GALVEZ, A., RAMÍREZ, M.J., GARCIA-GARIBAY, M. Chemical composition of mixture of single-cell protein obtained from Kluyveromyces fragilis and whey proteins. Archivos Latinoamericanos de Nutrición, Guatemala, v.40, p.252-261, 1990.

GOMES, P. Curso de estatística experimental. 11.ed. Piracicaba : Escola Superior de Agronomia Luiz de Queiroz, 1985. p.384.

GRANT, G., DORWARD, P.M., BUCHAN, W.C., ARMOUR, J.C., PUSZTAI, A. Consumption of diets containing raw soya beans (Glycine max), Kidney 
beans (Phaseolus vulgaris), cowpeas (Vigna unguiculata) or lupin seeds (lupinus angustifolius) by rats for up to 700 days: effects on body composition and organ weights. British Journal of Nutrition, London, v.73, p.17-29, 1995.

GUEDES, R.C.A. O cérebro desnutrido. Ciência Hoje, São Paulo, v.3, p.61-65, maio/jun. 1985

HENRY, C.J., PAYNE, P.R., GHUSAIN-CHOUEIRI, A. Relationship between tissue mobilization and storage in the rat. British Journal of Nutrition, London, v.78, p.131-134,1997.

HERNANDEZ, M., MONTALVO, I., SOUSA, V., SOTELO, A. The protein efficiency ratios of 30:70 mixtures of animal: vegetable protein are similar or higher than those of the animal foods alone. Journal of Nutrition, Bethesda, v.126, p.574-581, 1996.

HORWITZ, W. Official methods of analysis of the Association of Official Analytical Chemists. 3.ed. Washington DC: AOAC, 1975. p.1094.

INSTITUTO CUBANO DE INVESTIGACIONES DE LOS DERIVADOS DE LA CAÑA DE AZÚCAR. Santiago de Cuba, 1996.

LAM-SANCHEZ, A., SANTOS, J. E., TAKAMURA, K., TREPTOW, R.M.O., DUTRA DE OLIVEIRA, J.E. Estudos nutricionais com arroz (Oryza sativa L.). Alimentação e Nutrição, São Paulo, v.5, p.37-48, 1993/1994.

LEMOS, L.B., DURIGAN, J.F., FORNASIERE FILHO, D., PEDROSO, P.A.C., BANZATTO, D.A. Características de cozimento e hidratação de grãos de genótipos de feijão comum (Phaseolus vulgaris L.). Alimentação e Nutrição, São Paulo, v.7, p.47-57, 1996.

LOURENÇO, E.J., ZUCAS, S.M., PEREIRA, C.A.B. Influência da proteína da dieta sobre o desenvolvimento de órgãos-ensaio em ratos. Anais de Farmácia e Química de São Paulo, São Paulo, v.20, p.254-260, 1980

LOWRY, O.H., ROSENBROUGH, N.J., FARR, A.L., RANDALL, R.J. Protein measurement with the folinphenol reagent. Journal of Biological Chemistry, v.193, p.265-275, 1951

MARIATH, J.G.R., ZUCAS, S.M. Considerações sobre o valor nutricional da biomassa protéica de levedura. Boletim da Sociedade Brasileira de Ciência e Tecnologia de Alimentos, Florianópolis, v.13, p.21-28, 1980.

MARIATH, J.G.R. Influência da proteína isolada do resíduo de cerveja sobre o desenvolvimento do fígado de ratos. Ciência e Tecnologia de Alimentos, Campinas, v.3, p.199-210, 1983a.

MARIATH, J.G.R. Valor nutricional da proteína isolada do resíduo de cerveja. Associação Brasileira de Indústria de Alimentos, São Paulo, v.65, p.24-36, 1983b.

MIYADA, V.S., LAVORENTI, A. Uso da levedura seca (Saccharomyces cerevisiae) de destilarias de álcool de cana-de-açúcar na alimentação de suínos em crescimento e acabamento. Revista da Sociedade Brasileira de Zootecnia, v.8, p.497-515, 1979.

NATIONAL RESEARCH COUNCIL (USA). National Academy of Sciences. Nutrient requirements of laboratory animals. Washington DC, 1978.

PACHECO, M.T.B., CABALLERO-CÓRDOBA, G.M., SGARBIERI, V.C. Composition and nutritive value of yeast biomass and yeast protein concentrates. Journal of Nutrition and Science Vitaminology, v.43, p.601-612, 1997.

PESSOA, D.C.N., LAGO, E.S., FREITAS, L.P.C.G., ANTUNES, N.L.M., BION, F.M., MEDEIROS, R.B. Misturas de feijão e arroz de alto valor protéico. Revista Brasileira de Pesquisas Médicas e Biológicas, São Paulo, v.12, p.127-132, 1979.

PÓO, M.E., MILLÁN, N. Efecto de la concentración dietaria de la levadura (Saccharomyces carlsbergensis) recuperada de la cerveza, en pollos macho warren. Archivos Latinoamericanos de Nutrición, Guatemala, v.40, p.95-106, 1990.

PRAKASH, J. Rice bran proteins: properties and food uses. Critical Reviews in Food Science and Nutrition, v.36, p.537-552, 1996.

SARWAR, G. Dietary nucleotides/nucleosides may have important metabolic functions but free adenine may produce adverse affects. Journal of Nutrition, Bethesda, v.78, p.1037-1039, 1997.

SGARBIERI, V.C. Proteínas em alimentos protéicos: propriedades, degradações e modificações. São Paulo : Varela, 1996.

TEODÓSIO, N.R., LAGO, E.S., ROMANI, S.A.M., GUEDES, R.C.A. A regional basic diet from Northeast Brazil as a dietary model of experimental malnutrition. Archivos Latinoamericanos de Nutrición, Guatemala, v.40, p.533-545, 1990.

Recebido para publicação em 4 de julho de 2000 e aceito em 22 de novembro de 2001. 